Supporting Information

\title{
Casein-Hydroxyapatite Composite Microspheres for Strontium-Containing Wastewater Treatment
}

Shi Feng, ${ }^{a \Uparrow}$ Wenbo Yang, ${ }^{a \Uparrow}$ Lijing Zhang, ${ }^{a}$ Xintong Wang, ${ }^{b}$ Sifang Wang, ${ }^{b}$ Shengyang

$$
\operatorname{Tao}^{a, *}
$$

${ }^{a}$ School of Chemical Engineering, Dalian University of Technology, Dalian 116024, Liaoning, P.R. China

E-mail: taosy@dlut.edu.cn (S.T.)

${ }^{b}$ CFHI Dalian Engineering \&Technology Co.,Ltd, Dalian 116600, Liaoning, P.R.

China

I These authors contribute equally to this work. 


\section{Index}

1. Size distribution of microspheres (Figure S1)

2. Element percentage of the microspheres (Figure S2).

3. The effect of AMPA on the microsphere formation (Figure S3).

4. Microfluidic device (Figure S4).

5. Element percentage (Table S1).

6. Fitting parameters of pseudo-second-order model (Table S2). S8

7. Comparison of the adsorption capacity and $K_{\mathrm{d}}$ of different adsorbents (Table S3)...S9

8. Impact of contact time on the removal of $\mathrm{Sr}^{2+}$ (Figure S5)..... $\mathrm{S} 10$

9. Observation of adsorbent under range of temperature (Figure S6).

10. Observation of adsorbent under range of $\mathrm{pH}$ (Figure S7).

11. The $\mathrm{Ca} / \mathrm{P}$ ratio in the CS-HAP-AMPA samples (Figure $\mathrm{S} 8$ ).

12. Langmuir isotherm fitting parameters at $25^{\circ} \mathrm{C}$ (Table S4).

13. Langmuir adsorption isotherm of $\mathrm{Sr}^{2+}$ at $25^{\circ} \mathrm{C}$ (Figure S9). 


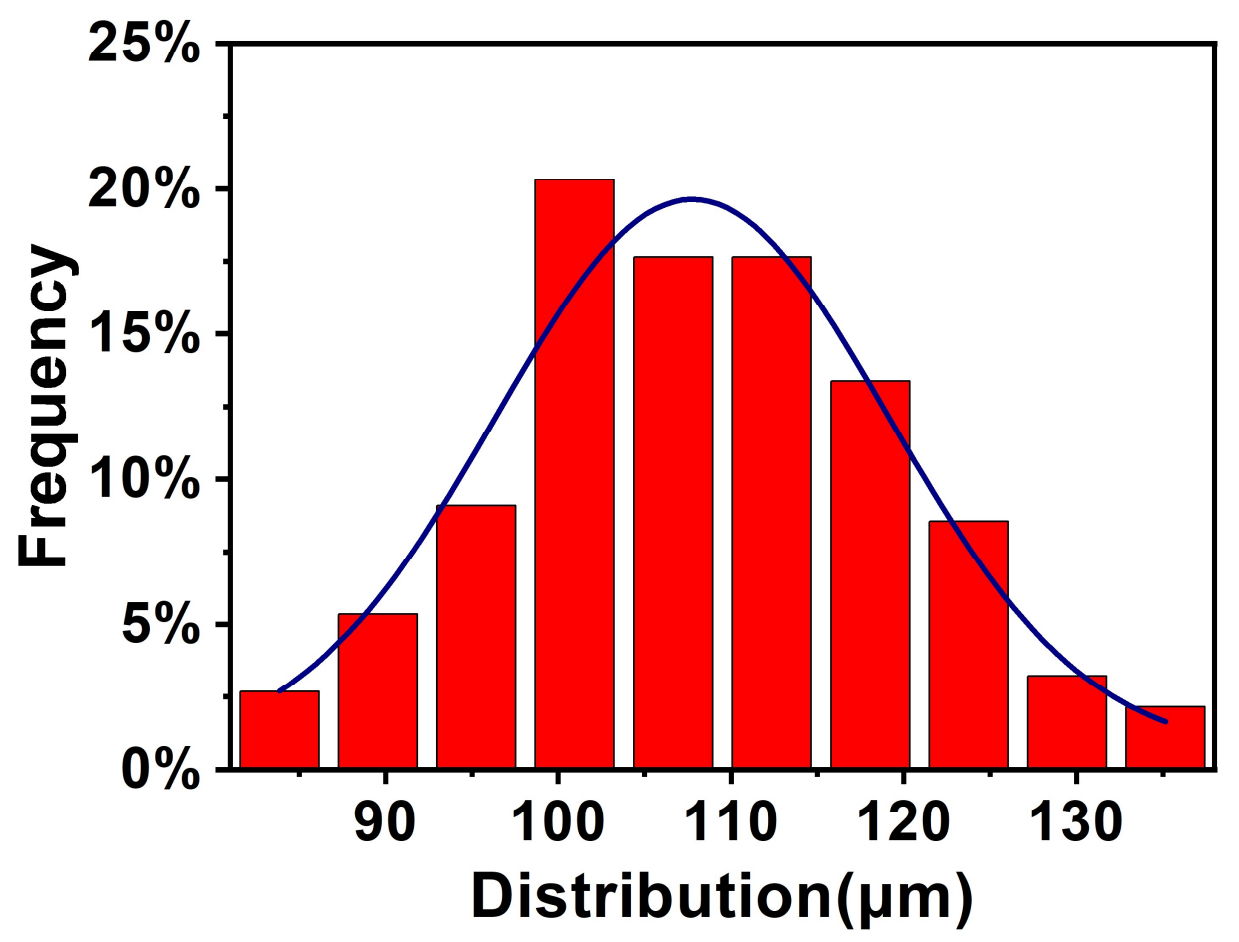

Figure S1. Size distribution of as-prepared microspheres. 

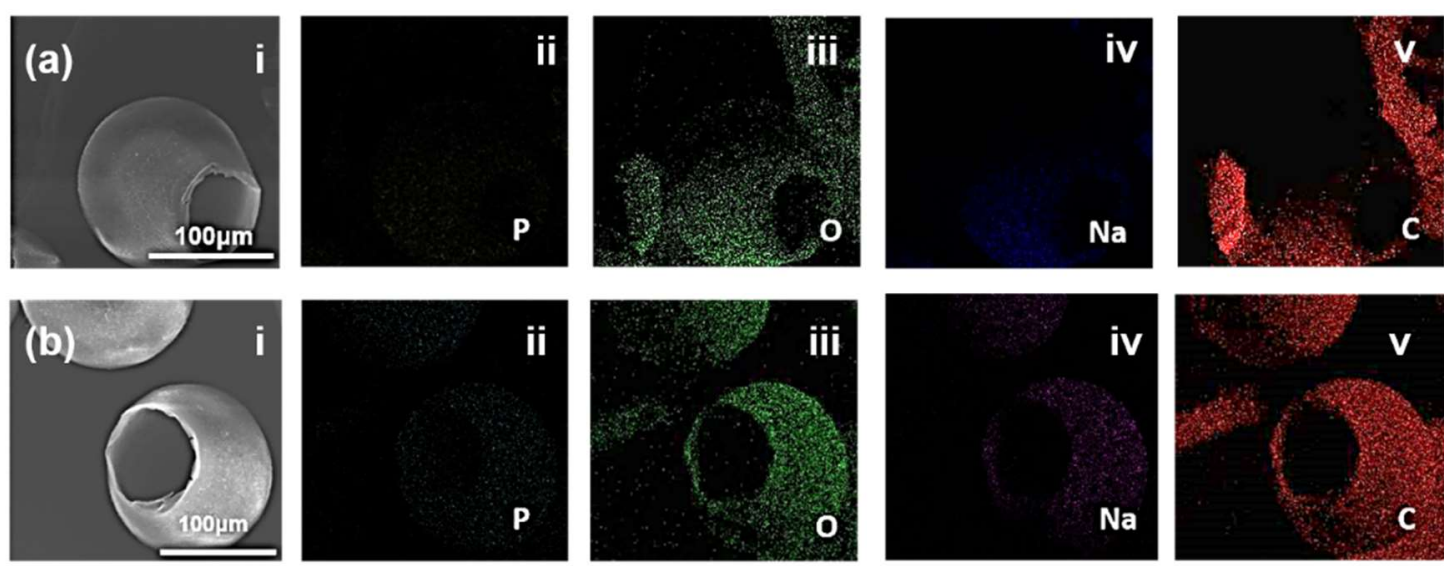

Figure S2. Mapping data of the microsphere with (a) AMPA addition, (b) without the addition. 


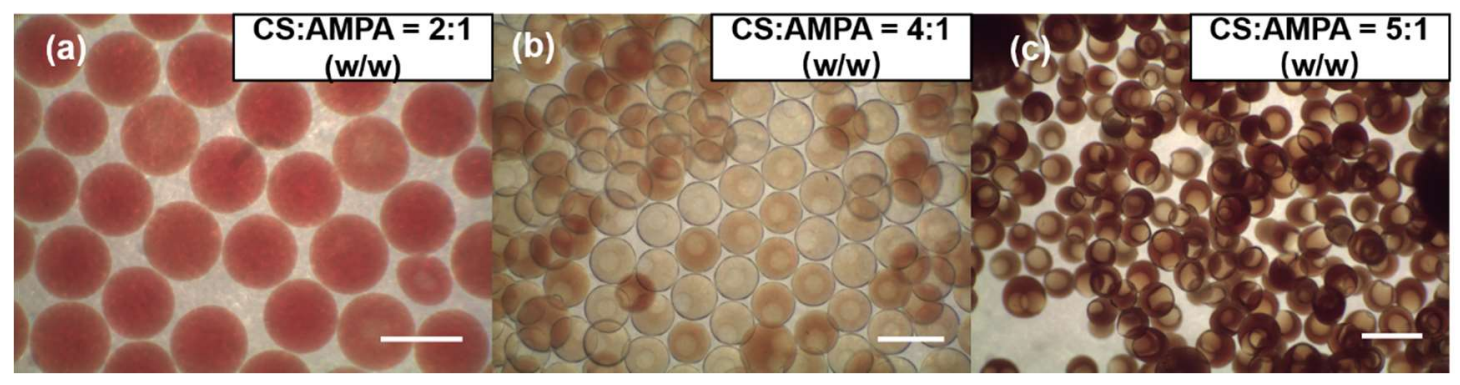

Figure S3. The excessive addition of AMPA would destroy the hollow structure and the double emulsion particles cannot be cross-linked completely; (a) The hollow structure can hardly be seen with the radio of $2: 1$. (b) The double emulsion particles cannot be solidified completely with the radio of 4:1. (c) The character of hollow was retained and the double emulsion particles were solidified normally with the radio of $5: 1$. The scale in the picture is $200 \mu \mathrm{m}$. 


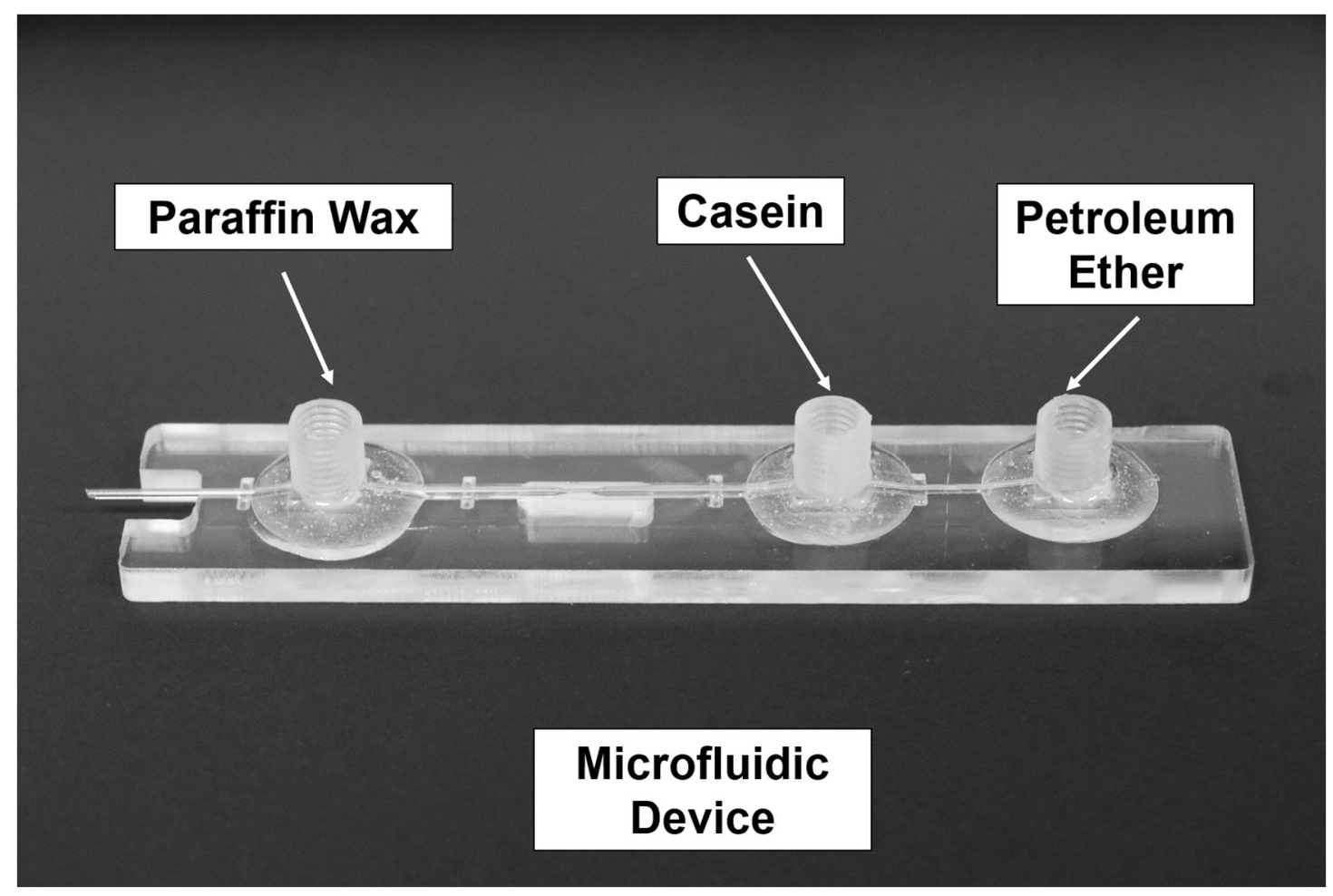

Figure S4. Microfluidic device used in this study. 
Table S1. Element Percentage of The Microspheres With And Without AMPA

\section{Addition}

\begin{tabular}{lllll}
\hline No APMA added & \multicolumn{3}{c}{ Containing AMPA } \\
Element & $\begin{array}{l}\text { Mass percentage } \\
(\mathrm{wt} \%)\end{array}$ & $\begin{array}{l}\text { Atomic } \\
\text { percentage }\end{array}$ & $\begin{array}{l}\text { Mass percentage } \\
(\mathrm{wt} \%)\end{array}$ & $\begin{array}{l}\text { Atomic } \\
\text { percentage }\end{array}$ \\
\hline $\mathrm{C}$ & 62.71 & 70.10 & 56.57 & 64.89 \\
$\mathrm{O}$ & 32.34 & 27.14 & 35.61 & 30.67 \\
$\mathrm{Na}$ & 4.08 & 2.38 & 6.21 & 3.72 \\
$\mathrm{P}$ & 0.87 & & 1.62 & 0.72 \\
& & 0.38 & & \\
\hline
\end{tabular}


Table S2. Fitting Parameters of Pseudo-Second-Order Model (Initial

\section{Concentration of $\mathrm{Sr}^{2+}=50 \mathrm{ppm}$ )}

\begin{tabular}{llll}
\hline pseudo-second-order & & & \\
Experimental values $q_{\mathrm{e}}(\mathrm{mg} / \mathrm{L})$ & Calculated $q_{\mathrm{e}}(\mathrm{mg} / \mathrm{L})$ & $K_{2}(\mathrm{~g} /(\mathrm{mg} \mathrm{h}))$ & $R^{2}$ \\
\hline 94.16 & 94.52 & 0.74 & 0.999 \\
\hline
\end{tabular}

\begin{tabular}{llll}
\hline pseudo-first-order & & & \\
Experimental values $q_{\mathrm{e}}(\mathrm{mg} / \mathrm{L})$ & Calculated $q_{\mathrm{e}}(\mathrm{mg} / \mathrm{L})$ & $K_{1}\left(\mathrm{~h}^{-1}\right)$ & $R^{2}$ \\
\hline 94.16 & 90.56 & 28.57 & 0.829 \\
\hline
\end{tabular}


Table S3. Comparison of The Adsorption Capacity And $K_{d}$ of CS-HAP-AMPA

Microsphere, CS-AMPA Microsphere, And Pure HAP

\begin{tabular}{lll}
\hline Adsorbents & $K_{\mathrm{d}}(\mathrm{mL} / \mathrm{g})$ & Adsorption capacity $(\mathrm{mg} / \mathrm{g})$ \\
\hline CS-HAP-AMPA microsphere & 4168.69 & 231.22 \\
CS-AMPA microsphere & 1735.00 & 138.89 \\
pure HAP & 1414.28 & 81.77 \\
\hline
\end{tabular}




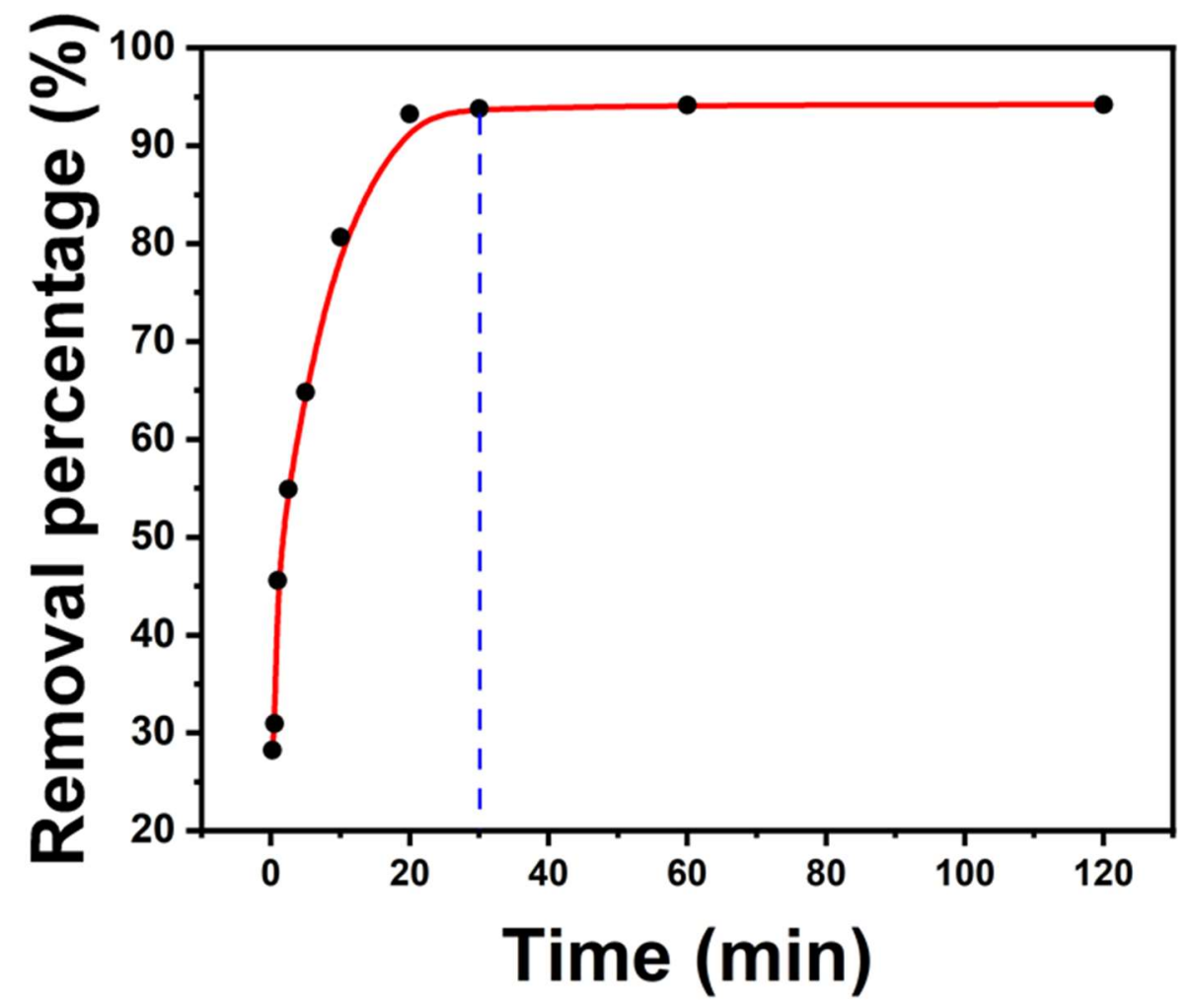

Figure S5. Impact of contact time on the removal of $\mathrm{Sr}^{2+}$ and the dash line is a guide of equilibrium time for the eye. 


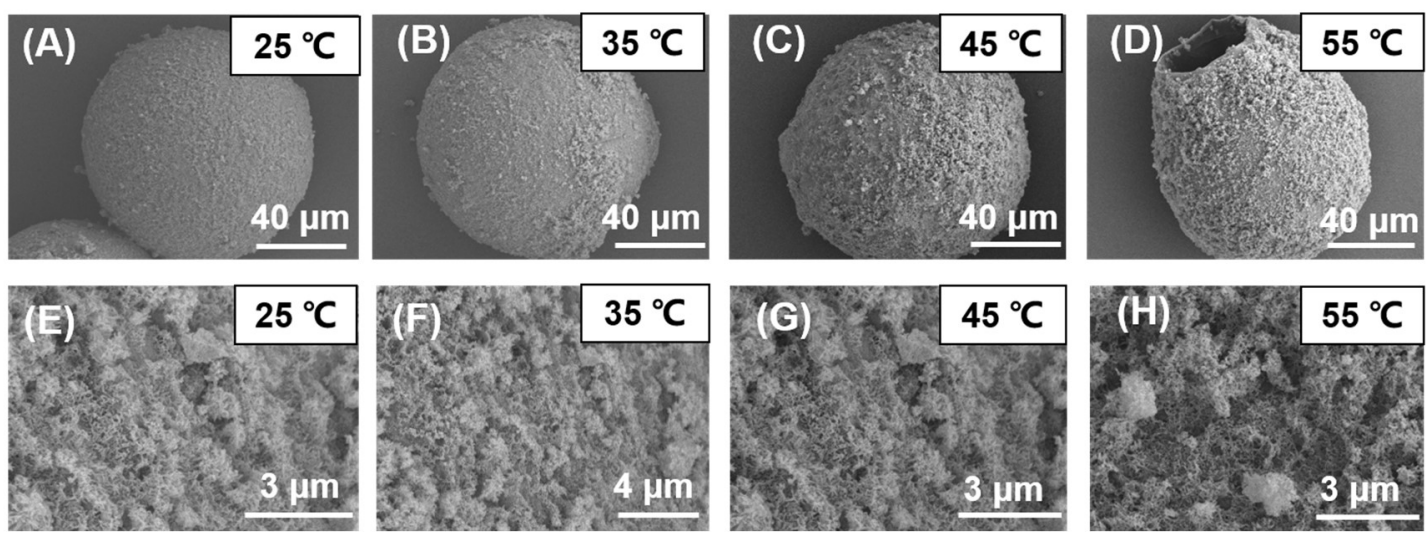

Figure S6. (A-D) SEM image of CS-HAP-AMPA at range of temperature and (E-H)

high magnification image of the crystalline morphologies on the surface of microsphere.
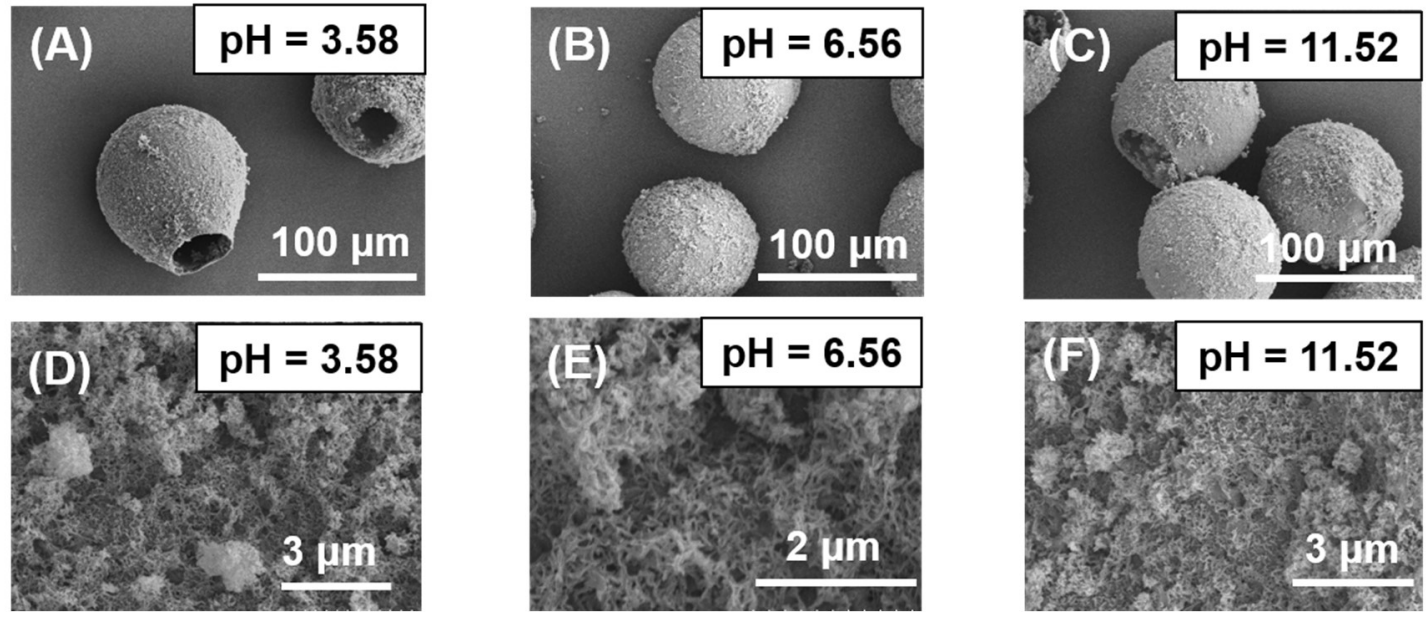

Figure S7. (A-C) SEM image of CS-HAP-AMPA at range of $\mathrm{pH}$ and (D-F) high magnification image of the crystalline morphologies on the surface of microsphere. 


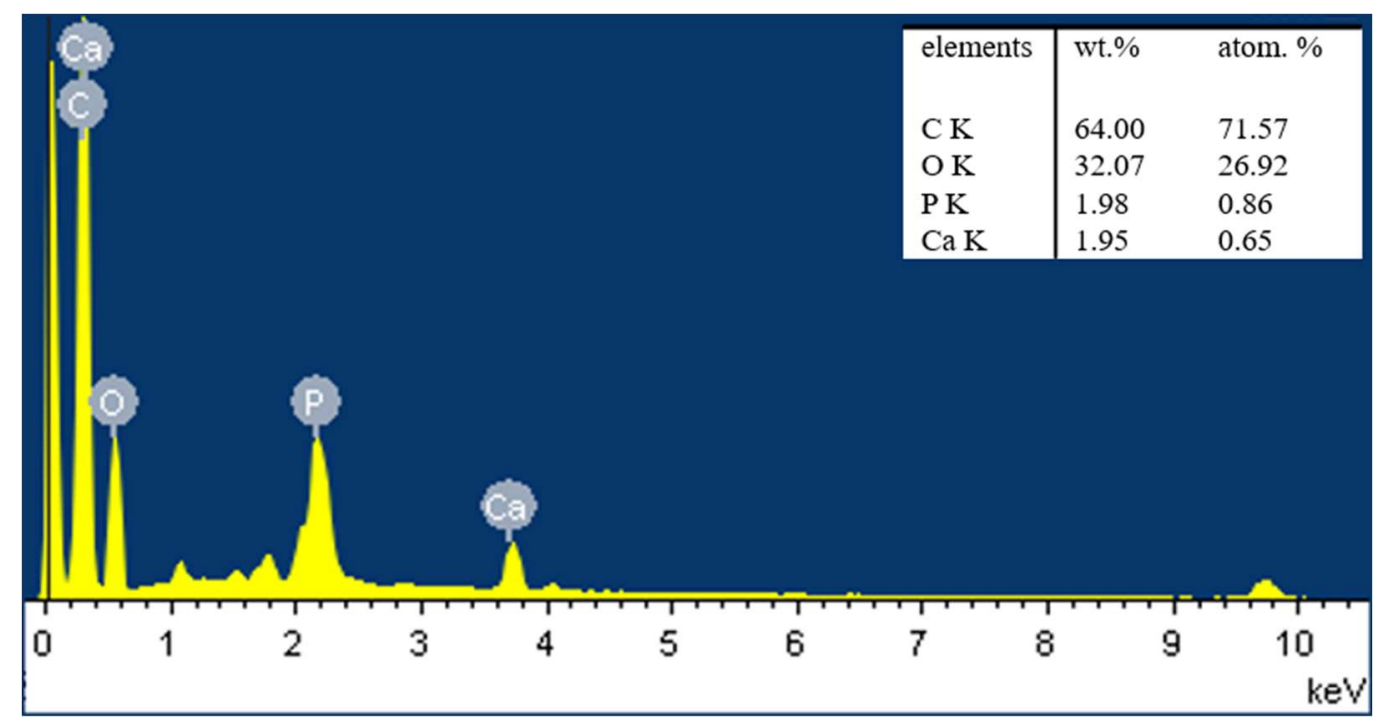

Figure S8. EDS analysis of the CS-HAP-AMPA microspheres. 
Table S4. Langmuir Isotherm Fitting Parameters at $25^{\circ} \mathrm{C}$

$$
\begin{aligned}
& \text { Langmuir model: } \\
& q_{\mathrm{e}}=\frac{b q_{\mathrm{max}} C_{\mathrm{e}}}{1+b C_{\mathrm{e}}}
\end{aligned}
$$

\begin{tabular}{lc}
\hline$q_{\max }(\mathrm{mg} / \mathrm{g})$ & 207.07 \\
$b(\mathrm{~L} / \mathrm{mg})$ & 0.619 \\
$R^{2}$ & 0.648 \\
\hline
\end{tabular}

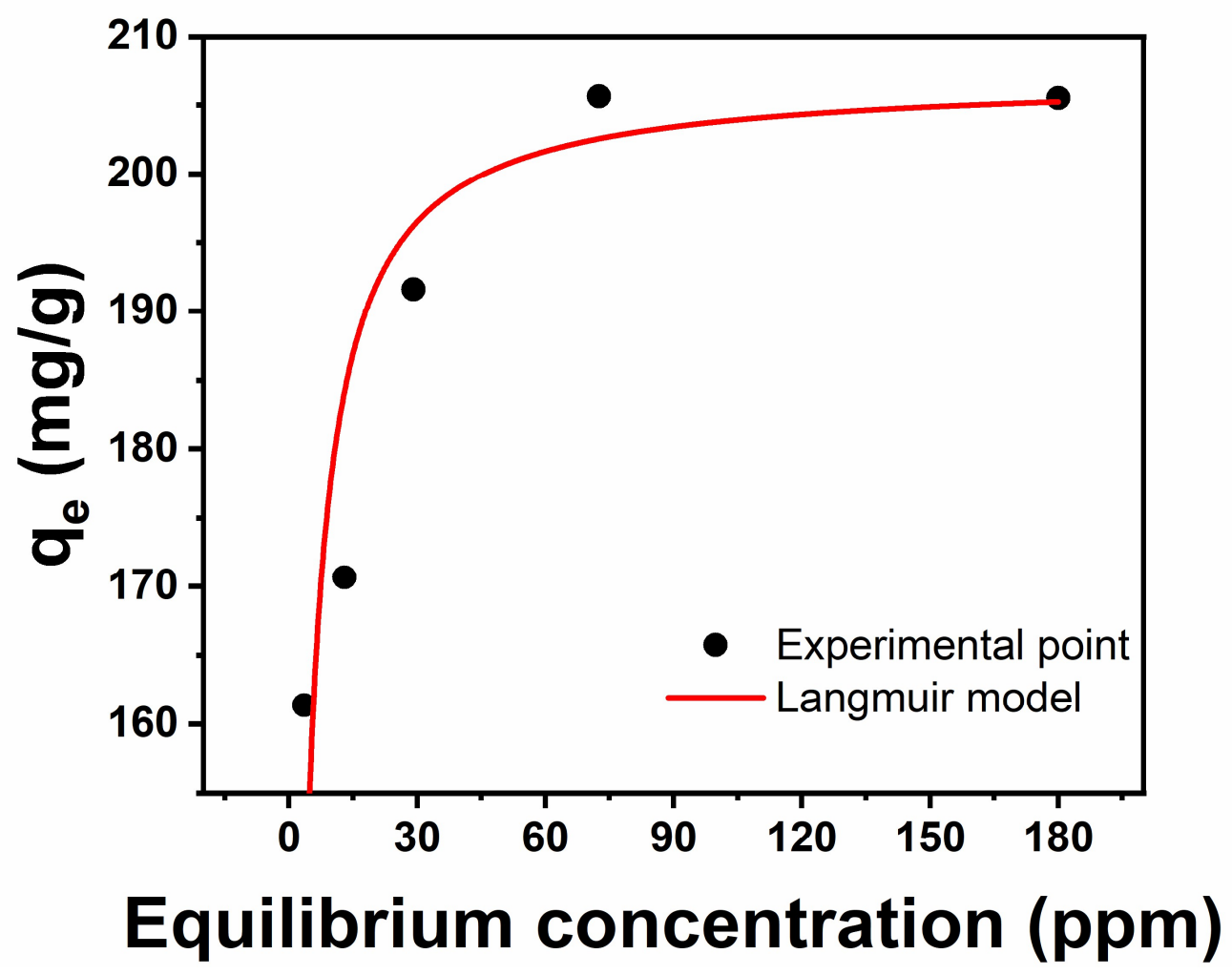

Figure S9. Langmuir adsorption isotherm of $\mathrm{Sr}^{2+}$ on CS-HAP-AMPA at $25^{\circ} \mathrm{C}$. The solid line represents the fitting data with the Langmuir model. 